\title{
A Case Study of Undergraduate Engineering Students' Computational Literacy and Self-Beliefs about Computing in the Context of Authentic Practices
}

\section{Introduction}

An important component for producing successful outcomes in engineering design and innovation is analytical problem solving ability, which remains central to engineering education (Litzinger et al., 2010). These analytical aspects supplement known best practices that include iterating through all the steps of the problem solving process, developing multiple solutions to the problem, and gathering sufficient information (Atman, Chimka, Bursic, \& Nachtmann, 1999). Modern engineering workplaces now use modeling and simulation practices, coupled with computational tools, to aid the analysis and design of systems (Emmott \& Rison, 2008; McKenna \& Carberry, 2012). Thus, these practices and tools have been widely acknowledged by the engineering community as important.

Early steps in the problem solving process involve generating the model of the system being studied and identifying a set of equations describing the system. It also involves using the model to propose a solution and then evaluating and validating the solution (Litzinger, et al., 2010). Facility with domain-specific software and computational tools has become an essential form of literacy for participating in the engineering problem solving process due to the increased complexity of engineered systems. We argue that engineering computational literacy consists of modeling and simulation processes, along with the underlying computational methods and techniques to actualize them.

Furthermore, domain-specific software and computational tools for analysis and design in engineering have reached a crucial level of development for integration into the learning cycle. Used in the context of authentic learning experiences, these tools can now support the integration of multiple cognitive processes and skills such as divergent and convergent thinking (Dym, Agogino, Eris, Frey, \& Leifer, 2005) within modeling and simulation processes relevant to engineering design and can accelerate the acquisition of core engineering concepts. These skills have been adopted across many disciplines as analytic tools that support the analysis of complex phenomena and as predictive tools that can anticipate the suitability of new designs.

Recognizing the importance of these skills, engineering education policymakers and the engineering education research community have recommended their incorporation into the curriculum. For instance, the Transforming Undergraduate Education in Engineering report ([ASEE], 2013) recently identified that industry professionals value programming skills and the ability to use computational tools to support problem solving. An ability to use the techniques, skills, and modern engineering tools necessary for engineering practice is a stated ABET (2013) student outcome. The Washington Accord (2011) stipulates program outcomes including (a) the application of knowledge of mathematics, science, engineering fundamentals to the conceptualization of engineering models, along with (b) the creation, selection and application of appropriate techniques, resources, and modern engineering tools, including prediction and modeling, to complex engineering activities, with an understanding of the limitations.

It has been widely acknowledged that engineering instructors and instructional designers are not keeping pace with the need for graduates with this complex skill set ([NRC], 2011; [WTEC], 2009; Emmott \& Rison, 2008; Guzdial, 2011). For example, students who decided to pursue a computational concentration in their graduate degrees expressed frustration and concerns about not being prepared to solve highly interdisciplinary and highly computationally complex problems (Magana \& Mathur, 2012). Students repeatedly reported a lack of common basic computational knowledge and insufficient exposure to computational engineering (i.e., computation to solve problems in their discipline) at the undergraduate level, receiving such training only late in their academic careers, i.e. at the master's or doctoral level (Magana \& Mathur, 2012). These research findings imply that acquiring computational literacy is a process that must be acquired over the course of a student's academic and professional career.

(C) 2016. This manuscript version is made available under the Elsevier user license http://www.elsevier.com/open-access/userlicense/1.0/ 
Experiences deploying programming, computational tools and software in the context of their discipline through repeated exposure may be crucial for students' acquisition of these highly desired skills. Also, students' selfperception of their abilities and interests in computation, which are arguably critical for their decisions to pursue careers that depend on such skills, may be quite sensitive to the nature of their exposure to programming, computation and software. For example, studies focusing on first-year students, have identified that computing abilities, problem-solving abilities, and understanding of disciplinary concepts, among others, are sources of confidence of engineering students' self-efficacy; where computing abilities are amongst the most influential (Hutchison-Green, Follman, \& Bodner, 2008; Hutchison, Follman, Sumpter, \& Bodner, 2006)

In this study, we specifically seek to explore the effect of the foundational computational preparation at the undergraduate level on students' self-beliefs and their ability to deploy computation to acquire conceptual knowledge in their field. In particular, we wish to understand whether "authentic" computational learning, i.e. learning situated within the context of their engineering discipline, early in students' undergraduate career (e.g., freshmen/sophomore) has an influence on their beliefs and performance in subsequently programming, applying computational tools, and using application software. It is important to note that this modality is not the norm currently, as most students are initially introduced to computation as a distinct discipline and only late in their academic careers, if ever, do they have the opportunity to deploy computation in an engineering context.

The context of this study is a Materials Science and Engineering (MSE) department at [University Name] that wanted to address this educational deficiency by preparing its students for the increasing role computation plays in the discipline. It implemented a curricular innovation across the core courses of the undergraduate program to introduce computer programming, modeling and simulation practices, and the application of engineering tools. The curricular innovation consists of a new discipline-based gateway computing course entitled "Computation and Programming for Materials Scientists and Engineers" (CPMSE), coupled with the integration of computational learning modules in the major's six core courses. The CPMSE course's primary learning goal is for students to apply algorithmic thinking and computer programming toward the solution of engineering and scientific problems relevant to MSE (Authors, 2013). The modules integrated into the subsequent core courses are designed to reinforce computational materials science and engineering (CMSE) skills and to facilitate the acquisition of foundational MSE concepts.

This study describes undergraduate materials science and engineering students' shifting self-beliefs and learning gains that resulted from the curricular innovation. Specifically, we investigated students' self-perceived abilities at performing various modeling, simulation and computation tasks, their perceived value of these skills in their academic and future professional careers, as well as the effectiveness of this approach to improve the learning of disciplinary concepts. Specific research questions for this study are:

1. Are there any differences in self-beliefs among students who have different prior programming experiences?

2. Are there any differences in disciplinary learning among students who have different prior programming experiences?

3. How do students' prior programming experiences relate to their self-beliefs and their disciplinary learning?

4. How do students' self-beliefs relate to each other and their disciplinary learning gains after exposure to authentic computational learning experiences?

\section{Student Self-Beliefs and Academic Achievement}

Educational researchers and psychologists, among others, have extensively investigated student self-beliefs as related to academic achievement. Self-belief constructs (i.e., self-efficacy, self-concept and self-esteem) describe a person's opinions of his or her own attributes and abilities as an individual (Bryne, 1996; Valentine, DuBois, \& Cooper, 2004). A meta-analysis of longitudinal studies aimed at finding the effect of self-beliefs, identified a small, favorable influence of student self-beliefs on academic achievement (Valentine, et al., 2004). Furthermore, stronger 
effects were identified when researchers evaluated self-beliefs associated to a specific domain or discipline (Valentine, et al., 2004).

In engineering education contexts it has been suggested that specifically, self-efficacy strongly influence choices engineering students may make (Hutchison-Green, et al., 2008). These influences can be positive or negative based on their perceptions of their abilities as related to a particular task (Hutchison, et al., 2006). Similarly, research suggests that students' self-efficacy, is positively related to indicators of cognitive engagement (Greene \& Miller, 1996). That is, students who feel more confident in their ability to perform a given task are more likely to engage their repertoire of learning strategies and persist at using those. Exploratory studies conducted at the freshmen level have identified that students' self-efficacy and anticipated future success decreased over the first year for both men and women (Jones, Paretti, Hein, \& Knott, 2010). These two constructs predicted achievement better than interest, importance and usefulness constructs. Constructs associated with interest, importance and usefulness predicted career plans for both men and women (Jones, et al., 2010).

\section{Engineering Computational Literacy and Authentic Learning}

Engineering computational literacy consists of modeling and simulation processes, along with the underlying computational methods and techniques to actualize them (Authors, in review). The term computational literacy, initially coined in the field of science education (diSessa, 2001), describes a new form of literacy in which computer software can change the way people think and learn important scientific ideas by creating and manipulating new computational representations (diSessa, 2001). The three pillars of literacy include (a) the material pillar consisting of external signs, symbols, depictions or representations; (b) the mental or cognitive pillar extending humans' reasoning capabilities; and (c) the social pillar where communities adopt, share, and extend the use of the literacy (diSessa, 2001). Based on these pillars, the processes of scientific discovery and reasoning can be aided by computational literacy through visualizing abstract patterns, and at the same time, supporting student abilities to make inferences (diSessa, 2001).

Meaningful computational literacy in engineering necessitates the adoption of a "practice perspective" (Roth \& McGinn, 1997, p. 92). In a practice perspective the focus of learning is on participation in authentic contexts. Because practice consists of a process of action and reflection in context (Ehn, 1993), we argue that learning through practice requires involving learners in authentic "field" experiences where they participate in (i) the process of collecting, transforming, and summarizing data and (ii) the representation of the relationship between the observed event and its re-representation (Roth \& McGinn, 1997). Authentic learning has widely been documented in the science education literature. Shaffer and Resnick (1999) performed an analysis of the literature to identify the different kinds of authentic learning. They identified four different kinds of authentic learning:

(a) learning that is personally meaningful for the learner, (b) learning that relates to the real-world outside of school, (c) learning that provides an opportunity to think in the modes of a particular discipline, and (d) learning where the means of assessment reflect the learning process (Shaffer \& Resnick, 1999, p. 195).

Shaffer and Resnick (1999) concluded that these four kinds of authentic learning are independent but complementary to each other. They proposed a "thick" view of authenticity arguing that in order to really achieve authentic learning, a combination of these four kinds is needed. Furthermore, the authors argued that computational media can provide the ability to simultaneously support the integration of some or all of these four kinds of authentic learning. We extend this premise into the engineering education arena arguing that well-designed computational exercises, including interactions with domain-specific software for analysis and design, are particularly well-suited to support authentic learning in engineering. We argue that such practices can have dramatic literacy implications in engineering because they can support the delineated three pillars of literacy. Thus, computational literacy in engineering can be apt not only for supporting student design, problem solving, and modeling and simulation, but also for acquiring core disciplinary concepts. However, the integration of some or all of these processes and skills 
into the undergraduate curriculum, although productive and relevant, may overwhelm novice learners due to the complexity of the task (Magana, Falk, \& Reese, 2013). Specifically, aspects of previous experiences and the student's sense of self-efficacy seem to play an important role in explaining student achievement, persistence, and interest (Hutchison, et al., 2006; Kinnunen \& Simon, 2012).

\section{Theoretical Framework}

Anchored instruction is the theoretical foundation that guided the integration of computation within disciplinary engineering knowledge and practices studied here. Anchored instruction is a cognitive perspective that aims to overcome the limitations of inert knowledge (The Cognition Technology Group at Vanderbilt [CTGV], 1990). Inert knowledge refers to information that is recalled when individuals are explicitly asked to do so, but may not be used spontaneously when relevant for problem solving (Whitehead, 1959). An example of inert knowledge was presented by Sherwood and colleagues (Sherwood, Kinzer, Hasselbring, \& Bransford, 1987), when they asked entering college-level students to explain how logarithms can be useful for problem solving. Researchers found that the majority of the students were unable to describe what logarithms are used for, even though they remembered learning them in school as part of their math exercises. Similarly, students found logarithms difficult to solve instead of finding them to be useful tools for problem solving. The goal of anchored instruction is to overcome the inert knowledge problem by creating learning environments that foster understandings of the kinds of problems and opportunities that experts encounter. It also applies the knowledge and tools experts use. The implications of anchored instruction for the design of learning environments relates to providing learners with opportunities that allow them to (a) meaningfully integrate concepts and theories by immersing them in the phenomena being investigated and to (b) experience the effects of incorporating new information into their own observations and understanding (CTGV, 1990). This is usually accomplished by anchoring instruction in complex problem spaces that can be explored for extended periods of time.

Anchored instruction can guide the design of learning experiences that can effectively promote the use of computation as a meaningful tool for engineering problem solving and design. This can be achieved by designing opportunities where learners can integrate disciplinary practices and tools contextualized within disciplinary knowledge by means of authentic tasks. Authentic tasks have been defined as "ordinary practices of the culture" (Brown, Collins, \& Duguid, 1989, p. 34). Authentic tasks occurring in real-life contexts are important because they can establish meaningful associations between learning experiences and connections among knowledge, skills and practices of a discipline (Choi \& Hannafin, 1995).

\section{Conceptual Framework}

Control-Value Theory of Achievement Emotions (Pekrun, 2006) is the conceptual framework that guided the evaluation of this investigation. The Control-Value Theory of Achievement Emotions is a comprehensive framework that considers the role of self-beliefs in academic achievement (Pekrun, 2006; Pekrun, Frenzel, Goetz, \& Perry, 2007). This theory postulates that the impact of learning environments is mediated by students' experienced appraisals. It is assumed that features of learning environments are of critical importance for students' beliefs (Pekrun, 2006). For this study our goal was to investigate how computation, delivered through anchored instruction within engineering practices would impact student self-beliefs and whether these could explain differences in students' academic performance. Under this framework student-experienced emotions during a specific task will depend on their perceived level of control of the outcome (control appraisals) and their perceived importance of achieving that outcome (value appraisals). These emotions consequently may have a direct impact on student academic performance (Pekrun, et al., 2007). Emotions influence cognitive resources, motivation, metacognition, and self-regulation which affect engagement and performance. Then, the process of learning and their achievement outcomes are expected to provide a feedback loop on student emotions and beliefs (Pekrun, et al., 2007). 
Control-Value Theory defines achievement emotions as "emotions tied directly to achievement activities or achievement outcomes" (Pekrun, et al., 2007, p. 15). Three types of achievement emotions are presented: prospective-outcome emotions are experienced when individuals expect positively-valued success or negativelyvalued failure; retrospective-outcome emotions are experienced when important successes and failures do not depend on subjective control; and activity emotions are experienced when achievement activities depend on the perceived controllability of the activity and its value.

The focus of this paper is centered upon the impact of computation delivered by traditional methods or by authentic learning experiences in the form of anchored instruction, and how they relate to each other. A simplified version of the Control-Value Theory framework was adapted for this study. As shown in Figure 1, this case study aims to identify student current control and value appraisals of engineering computational literacy such as modeling, simulation and computation practices. In this context, control appraisals are specifically focused on self-efficacy beliefs. Self-efficacy refers to individuals' subjective convictions in their capabilities to organize and execute actions that are required to achieve a desired outcome in a given context (Bandura, 1977). It also investigates the relationship between student control and value appraisals with academic performance.

\section{Antecedents}

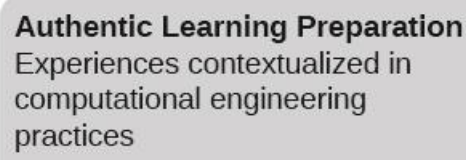

Traditional Preparation

Previous computing courses

(zero, one, two, three to five)

\section{Self-beliefs}

\section{Control Appraisals}

The degree to which an individual believes in their aptitude or

competence in using computation successfully

\section{successfully}

\section{Value Appraisals}

The degree to which an individual

believes that using computation

would enhance his or her

academic and work performance

\section{Effects}

\section{Academic performance} Individuals' ability to improve their understanding of disciplinary concepts via engagement with computational learning experiences.

Figure 1. Adaptation of the Control-Value Theory for the design of the study.

\section{Curricular Innovation}

The Materials Science and Engineering (MSE) department at [name University here] implemented a curricular innovation to introduce computational methods and skills across the core courses of the undergraduate program. The curricular innovation consists of a new discipline-based computing course entitled "Computation and Programming for Materials Scientists and Engineers" (CPMSE), coupled with the integration of computational learning modules in the major's six core courses to simultaneously reinforce CMSE skills and foundational MSE concepts. The characteristics of these two efforts are explained below.

\subsection{Computation and Programming for Materials Scientists and Engineers (CPMSE) Course}

The CPMSE course is a gateway course designed for first-year MSE students, although students from outside the major and upper division undergraduates who transfer into the major also enroll. The course's primary learning goal is for students to learn algorithmic thinking and computer programming in the context of solving engineering and scientific problems relevant to MSE (Magana, et al., 2013). The design of the CPMSE course was guided by two assumptions: 
a) computational thinking is best realized in domain-specific, personally-relevant contexts ([NRC], 2011)

b) transfer of learning is better promoted when the following conditions are implemented:

- emphasizing understanding rather than memorization,

- providing learners with enough time to develop patterns of recognition, and

- providing students deliberate practice in authentic contexts with feedback (Bransford, 2000).

The learning objectives of CPMSE are for the students to be able to: (i) write MATLAB programs to execute welldefined algorithms; (ii) design algorithms to solve engineering problems by breaking these into small tractable parts; and (iii) model physical and biological systems by applying linear systems and ordinary and partial differential equations. This course applied the How People Learn (HPL) framework (Bransford, 2000) with the goal of promoting effective learning transfer by placing an emphasis on learning rather than on teaching. The way we implemented HPL framework's intersecting components were as follows.

a. knowledge centered in which foundational knowledge skills and attitudes were based on applying algorithmic thinking and computer programming toward the solution of engineering and scientific problems;

b. learner centered in which learning materials connected students' prior knowledge and interests while at the same time reinforced and developed their computing concepts, methods, and practices through real-world applications of interest to their majors;

c. community centered where students collaborative learning was promoted during class time and outside the classroom work; and

d. assessment centered in which learners were provided with real time feedback from the instructor and teaching assistant during and outside of class, thus providing them with multiple opportunities to demonstrate their knowledge and receive iterative and constant feedback.

To support the course objectives while following the guidelines of the HPL framework, the course employed an inverted classroom design method (Gannod, Burge, \& Helmick, 2008; Lage, Platt, \& Treglia, 2000). For instance, a typical learning module would start by having students watch a lecture online and then respond to a multiple-choice quiz prior to the class meeting time. Then, during the class meeting time, students would collaboratively solve a series of exercises to predict the outcome of a code, debug a given code, or implement a solution to a problem. Five larger projects were assigned through the course of the semester along with a student-designed final project. Inclass, out-of-class (i.e., office hours) and online discussions were held to provide feedback and support to students while they worked on their projects. MATLAB ${ }^{\circledR}$ was used as the computational software and programming environment to implement all exercises and assignments of the course.

\subsection{Modules in Disciplinary Core Courses}

In addition to the CPMSE course, the instructional innovation also consisted of implementing computational modules as part of the six core courses of the MSE degree that students generally took after completing the CPMSE course. Learning modules were designed with the following overarching learning goals in mind: (a) give students extended exposure to computational tools that can help them solve disciplinary problems, (b) provide them with modeling and simulation skills, and (c) reinforce conceptual understanding of disciplinary concepts.

The process of designing and validating the learning modules consisted of having a disciplinary and computational expert, Author 3, work one-on-one with each of the instructors of the six MSE core courses. During the first oneon-one meeting between Author 3 and the professor, both identified which topics of the course were good candidates for teaching with a computational module. During that session, both individuals drafted ideas about the content of the module as well as an implementation schedule. Author 3 then independently created a first version of the learning module that was shared with the educational experts, Author 1 and Author 4, to refine wording, learning objectives, and alignment with assessments. This version was then sent to the course instructor for further feedback. Table 1 describes the disciplinary goal and the computational goal for each of the learning modules implemented. 
Disciplinary goals refer to those learning objectives related to the acquisition of course-specific materials science and engineering concepts that were reinforced via the computational modules. Computational goals were the problem-solving strategies and inquiry skills related to modeling, simulation, computing and data analysis that were reinforced by the computational modules. Table 1 also describes the computational software used along with the nature of engagement required of the student.

One important feature of the modules was that each differed in the nature of engagement required of the student in the manipulation of the underlying model. Here we make a further distinction based on the student ability to not only inspect the underlying model, but also the requirement that they modify the equations or algorithm of the underlying model to achieve a satisfactory result (Murray, Winship, Bellin, \& Cornell, 2001). When the students manipulated the model via a graphical user interface, or by inspecting but not altering the underlying model, only changing some input parameters, we called this a configuring approach. On the other hand, when students were asked to modify the model by manipulating the underlying computer code, we called this a programming approach.

Table 1. Description learning modules and objectives

\begin{tabular}{|c|c|}
\hline \multirow{2}{*}{\multicolumn{2}{|c|}{$\begin{array}{cc}\text { Learning Modules } & \text { Learning Goals (Computational Software - } \\
\text { Biomaterials 1: Simulating Polymerization Reactions (MATLAB }- \text { Configuring) }\end{array}$}} \\
\hline & \\
\hline & hemical kinetics influence molecular weight \\
\hline om & tion. \\
\hline
\end{tabular}

Structures 1: Monte Carlo Simulation of Alloys and Compounds (MATLAB - Programming)

Disciplinary goal: Identify the role of order parameters in relation to phase transitions

Computation goal: Apply basic Monte Carlo algorithm, calculate order parameter in simple simulated system, compare to theoretical prediction

Structures 2: Simulating a Polymer Random Walk (MATLAB - Configuring)

Disciplinary goal: $\quad$ Understand the self-avoiding random walk and polymer conformations

Computation goal: Generate and plot data and compare to theoretical prediction

Thermodynamics 1: Van der Waals Gas (Mathematica - Programming)

Disciplinary goal: Understand scaling in the VdW equation of state, dimensionless quantities

Computation goal: Generate and plot mathematical expressions and compare using self-generated GUI.

Thermodynamics 2: Statistical Mechanics of Magnetic Response (Ising Model) (MATLAB - Programming)

Disciplinary goal: $\quad$ Understanding the Ising model and how statistical mechanics can be used to perform thermodynamic averages.

Computation goal: Understand basic Monte Carlo algorithm, calculate order parameter in simple simulated system, compare to theoretical prediction

Thermodynamics 3: Calculation of Phase Diagrams (Thermo-Calc - Configuring)

Disciplinary goal: Understand the connection between free energy and phase diagrams, interpreting phase diagrams to solve materials design problems

Computation goal: Generate plots from thermodynamic package, use these to make predictions.

Electronic Properties 1: Quantum wave packets (MATLAB - Programming)

Disciplinary goal: Understand wave packets and the relation between wavelength, frequency, momentum and energy as well as superposition.

Computation goal: Visually represent complex (imaginary and real) and time dependent data in one dimension.

Electronic Properties 2: Finite Wells and Superlattices (MATLAB - Configuring)

Disciplinary goal: Understand the relation between quantum well depth, width and number along with energies of quantum states, examine the formation of symmetric and anti-symmetric states and the emergence of bands due to interactions between localized states.

Computation goal: $\quad$ Run simulations, collect data, plot results and compare to theory.

Mechanical Properties 1: Necking in Bars (COMSOL - Configuring)

Disciplinary goal: Observe the difference between elastic and plastic deformation, understand conditions for formation of a neck, analyze stress and strain in 3D.

Computation goal: Parameterize and set boundary conditions for a finite element model, analyze and interpret results. 


\begin{tabular}{cl}
\hline $\begin{array}{c}\text { Mechanical Properties 2: } \\
\text { Disciplinary goal: }\end{array}$ & $\begin{array}{l}\text { Understand the evolution of dislocations under stress, their interactions with each } \\
\text { other and with inclusions, formation of Orowan loops, roles of line tension and } \\
\text { stress. }\end{array}$ \\
Computation goal: & Run simulation and analyze data, alter simulation to explore different physics.
\end{tabular}

Table 1 indicates the four different software tools students used to solve the challenges posed in each module, along with the provided level of access to the algorithmic model. MATLAB $®$ is a numerical computing environment and fourth-generation programming language that facilitated a configuring or a programming approach. Thermo-Calc ${ }$ is a specialized scientific software and databases used for calculations involving computational thermodynamics and diffusion of controlled simulations that facilitated a configuring approach. Mathematica is software that supports technical computing by means of symbolic language, mathematical computation, numerics, visualization, algebraic manipulation and number theory that facilitated a programming approach. COMSOL $®$ is a finite element analysis, solver and simulation software that facilitated a configuring approach. While MATLAB was introduced in CPMSE, the other software tools were introduced in the context of the modules in the six core courses.

All modules were introduced by the same instructor and in a similar fashion implemented in a two-class session format during the span of one week. The day the module was introduced, class started with a brief introduction of the guest instructors (Author 3 and a postdoctoral student) followed by an introduction to the computational module (Author 4 undertook classroom observations). The computational module was briefly introduced in a four-step procedure that typically took no more than 10 minutes: (1) the guest instructor and the course instructor introduced the context of the module to the class; (2) the instructors explained how the module related to course content and to specific concepts previously taught; (3) the instructors briefly explained the underlying mathematical and computational representations. Students were then provided with the computational module document that introduced in detail the computation or algorithmic aspects of the module and, where deemed essential, how to operate the graphical user interface. The rest of class time was used for students to work on the modules. Instructors helped students individually as they worked on the modules during this class, clarifying confusing aspects as needed. Author 3 and a postdoctoral student held office hours during that week so students could receive additional, personalized assistance during the assignment.

\subsection{Possible Pathways of Exposure to the Curricular Innovation}

The components of the curricular innovation were implemented in three delineated steps as follows: during the spring 2012 semester the first implementation of the CPMSE course took place; during the fall 2012 semester computational modules were deployed as part of three of the six MSE core courses; and during the spring 2013 semester the second implementation of the CPMSE took place along with the deployment of computational modules as part of the remaining three disciplinary core courses. Although the curricular innovation was implemented in three well-delineated steps, students could have followed different paths of exposure. Students selected different curricular paths for various reasons. These include the fact that students who major in MSE may join the program late having previously taken computing classes, such as the standard introduction to programming in the computer 
science department that is offered in Java or Python. That would permit them to place out of CPMSE, and to engage in computational modules without the disciplinarily contextualized CPMSE preparation. Students take their core classes in different sequences sometimes foregoing the earliest available offering to take advantage of sporadically offered electives that may conflict with the core classes. This flexibility allows students to personally optimize their educational experience, although it prevents standard sequencing of the core MSE curriculum. Additionally, students who are not MSE majors take MSE courses to fulfill their own program requirements or purely for their own edification. Figure 2 depicts six possible general paths students could have followed (although other possible paths could have occurred). Students typically would not have taken all of the disciplinary core courses, and therefore not all of the modules, during any given semester.

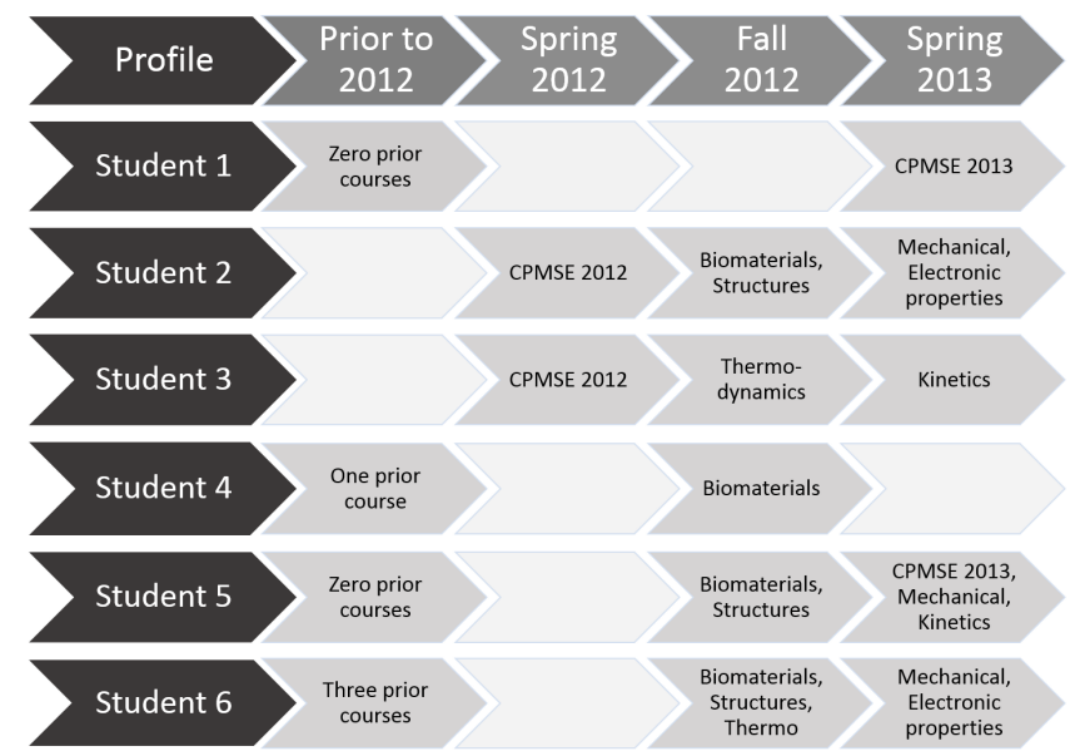

Figure 2. Profiles of possible Paths Followed by Students as Part of the Curricular Innovation

One possible path, which would represent the primary path envisioned by the curricular design, was that students were exposed to the CPMSE course in 2012 and then to some or all of the computational modules in the following semesters (e.g., profiles 2 or 3 in Figure 2). Another was that students were neither exposed to any preliminary programming courses nor to the CPMSE course, and their first exposure to the innovation was when they encountered one of the computational modules as part of a certain disciplinary course (e.g., profile 5 in Figure 2). These students would typically be students from outside MSE enrolling in MSE courses or students who had transferred into MSE and started taking MSE core courses before fulfilling their computing requirement (e.g., profile 4 in Figure 2 are likely biomedical engineering students fulfilling a requirement). A third possible scenario was that students obtained computing preparation as part of other courses and were then exposed to the computational modules as part of the disciplinary courses (e.g., profiles 4 or 6 in Figure 2). Finally, another common scenario for $1^{\text {st }}$ year MSE majors was that students were exposed to the CPMSE course in 2013 (e.g., profile 1 in Figure 2). Students who were exposed to the CPMSE course in both 2012 and in 2013 (n=5) as well as students who were simultaneously exposed to the CPMSE course in spring 2013 and to the disciplinary modules deployed in core courses $(n=8)$ were removed from the final analysis due to the small sample size.

\section{Methods}

A case study method was used to analyze and report the findings of this investigation. Case study refers to "an empirical inquiry that investigates a contemporary issue in depth within its real-life context, especially when the boundaries between phenomenon and context are not clearly evident" (Yin, 2009). Case study approach, as opposed to an experimental design, will allow us to "learn something" rather than "prove something" (Eysenck, 1976, p. 9). Thus, case study was particularly appropriate for this investigation because it allowed us to investigate the effects of 
the curricular innovation to enhance learning and teaching (Case \& Light, 2011). Case studies can allow the identification of individuals' behaviors, perceptions and attitudes that can be identified by means of data collected from multiple sources (Yin, 2009). Descriptive case studies in particular, aim to describe an intervention on the real-life context in which it occurred (Baxter \& Jack, 2008). For this particular descriptive case study, the unit of analysis consisted of the whole curricular innovation in which our goal was to characterize students' current control and value appraisals of engineering computational literacy, and how these appraisals as well as their preparation relate to student academic performance. Data collected was primarily quantitative. The use of quantitative analysis in case studies can be used either on its own or to complement qualitative analysis (Korzilius, 2010; Yin, 2009), so for this particular case our analysis is limited to quantitative evidence.

\subsection{Participants}

The participants of this study were undergraduate engineering students at [name University here]. The majors of the 130 students who completed both the pre-semester and post-semester surveys are: Materials Science and Engineering (48), Biomedical Engineering (51), Chemical and Biomolecular Engineering (13), Environmental Engineering (11), General Engineering (2), Biophysics (1), Chemistry (1), Computer Engineering (1), Computer Science (1), and Electrical Engineering (1). Ninety-three students took part in the experiment in the fall 2012 and 37 students participated in the spring 2013 semester. During the study, the students were exposed to the computational learning modules in the following courses: Structure of Materials ( $N=16)$, Thermodynamics $(\mathrm{N}=25)$, Biomaterials $(\mathrm{N}=65)$, Mechanical Properties $(\mathrm{N}=14)$, Electronic Properties $(\mathrm{N}=14)$, and Kinetics $(\mathrm{N}=16)$. Several students took multiple courses simultaneously. Table 2 summarizes the number of previous computing courses students completed and the numbers of modules the students were exposed to.

Table 2. Number of students per number of exposed courses

\begin{tabular}{lcc}
\multicolumn{1}{c}{ Variable } & Number of Students \\
\hline Number of Prior Computing Courses & & \\
Zero & 12 & 9.23 \\
One & 38 & 29.23 \\
Two & 31 & 23.85 \\
Three to Five & 14 & 10.77 \\
CPMSE-2012* & 11 & 8.46 \\
CPMSE-2013 & 24 & 18.46 \\
\hline Number of Exposed Modules & & \\
Zero & 28 & 21.54 \\
One & 59 & 45.38 \\
Two & 9 & 6.92 \\
Three & 23 & 17.69 \\
Four or more & 11 & 8.46 \\
* If the student was exposed to CPMSE-2012 and other previous courses, he or she was only considered in the CPMSE-2012 group
\end{tabular}

\subsection{Data Collection Method}

Self-Belief Measures. A Likert-scale survey was designed to measure three specific constructs associated with the Control-Value Theory. The first construct measured Control Appraisals, using four questions. The second construct measured Value Appraisals with four statements. The statements were jointly developed by the team members and were pilot-tested in a disciplinary computing course (Authors, 2013). After the first implementation some questions were added and others revised. All statements and their associated constructs are shown in Table 3 . We used a fivepoint Likert-scale for each of the statements (Likert, 1932). Students taking at least one of the courses under study were presented the survey at the beginning and end of each semester to measure the change in responses over the semester. 
Table 3. Survey statements grouped by constructs of the Control-Value Theory

\begin{tabular}{|c|c|c|}
\hline Constructs & ID & Statements \\
\hline \multirow{4}{*}{$\begin{array}{l}\text { Control } \\
\text { Appraisals }\end{array}$} & Q1 & I have the ability to design an algorithm. \\
\hline & $\mathrm{Q} 2$ & I have the ability to write a computer program. \\
\hline & Q3 & I have the ability to visualize data using a computer. \\
\hline & Q4 & I have the ability to implement a graphical user interface. \\
\hline \multirow{4}{*}{$\begin{array}{c}\text { Value } \\
\text { Appraisals }\end{array}$} & Q5 & $\begin{array}{l}\text { I feel computation (data visualization, modeling and simulation algorithm design) will be useful } \\
\text { in my studies. }\end{array}$ \\
\hline & Q6 & $\begin{array}{l}\text { I feel computation (data visualization, modeling and simulation algorithm design) will be useful } \\
\text { in my career. }\end{array}$ \\
\hline & Q7 & $\begin{array}{l}\text { I intend to purposefully seek courses that will allow me to increase my knowledge about } \\
\text { computation. }\end{array}$ \\
\hline & Q8 & $\begin{array}{l}\text { I intend to use computation (data visualization, modeling and simulation algorithm design) in my } \\
\text { future career. }\end{array}$ \\
\hline
\end{tabular}

Learning Measures. Learning measures were collected by means of a 3 to 5 multiple-choice question assessment measuring disciplinary learning goals for each module. The questions for each of the assessments were aligned with the disciplinary learning objectives as described in Table 1 above. In order to describe how these learning objectives were transformed into test questions, consider the disciplinary goal for the module denoted as Thermodynamics 2 which states that students will learn "...how statistical mechanics can be used to perform thermodynamic averages." Because it is typically impossible to enumerate all states in most systems of practical interest, Monte Carlo methods compute an approximation of the equilibrium average by visiting states in the system with the same probability that they would occur in equilibrium. (This is known as "importance sampling.") Though not all states are visited, the computed value will be a good approximation of the equilibrium expectation value because the states sampled are representative of the equilibrium system. The question posed to the students to test that this disciplinary goal was achieved is shown in Figure 3.

Additional specific assessments will be provided as supplementary electronic materials. The ad-hoc learning assessments were jointly created by two disciplinary experts (i.e., the course instructor and a co-author), and validated by a third one (i.e., a postdoctoral student). These instruments were then revised by two social scientists that provided feedback on the structure, length, wording and presentation of the materials. The questions were written to test common misconceptions that, according to the course instructor, students have experienced in previous semesters, which are also aligned with the foundational disciplinary learning goals in that particular course.

When computing an expectation value it is most important that
A. every state is included in the calculation
B. the lowest energy states are included in the calculation
C. the states with the highest multiplicity are included in the calculation.
D. a representative sample of states are included in the calculation.

Figure 3. An example assessment question used to assess one of the learning objectives for the Thermodynamics 2 module. $\mathrm{D}$ is the correct answer.

\subsection{Measures of Validity and Reliability}

We used a total of 324 student responses to the survey questions to assess validity and reliability. These responses were collected on several semesters, including the ones that are analyzed in this study. Cronbach's alpha was used to measure the reliability of the self-belief measures (Cortina, 1993). The alpha value for all items exceeded 0.8, a 
recommended threshold for research, as follows: control appraisals (pretest $=0.86$, posttest $=0.80$ ), and value appraisals (pretest $=0.90$, posttest $=0.91$ ). Pearson correlation was applied to evaluate convergent validity (see Table 4). The lowest correlations within each constructs were $0.47(\mathrm{Q} 2, \mathrm{Q} 4), 0.62(\mathrm{Q} 5, \mathrm{Q} 7)$. Moreover, the lowest values within correlations were reasonably higher than those correlations in different constructs.

The factor analysis confirmed the relationship between the first four questions to the control appraisal construct. The method for this factor analysis was maximum likelihood and the rotation was varimax. This analysis also confirmed that questions five to eight are assessing the value appraisal construct. Table 5 depicts the questions' loadings for the two factors (i.e., control appraisals and value appraisals)

Table 4. Convergent validity of measurements - Pearson correlation

\begin{tabular}{ccccccccc}
\hline & \multicolumn{4}{c}{ Control } & \multicolumn{5}{c}{ Value } \\
\cline { 2 - 9 } Q1 & Q1 & Q2 & Q3 & Q4 & Q5 & Q6 & Q7 & Q8 \\
Q2 & $\mathbf{0 . 8 0 1 8 1 4}$ & 1 & & & & & & \\
Q3 & $\mathbf{0 . 6 1 3 6 0 9}$ & $\mathbf{0 . 6 4 2 2 3 5}$ & 1 & & & & & \\
Q4 & $\mathbf{0 . 4 8 1 9 1 4}$ & $\mathbf{0 . 4 6 7 4 5 6}$ & $\mathbf{0 . 5 3 3 3 1}$ & 1 & & & & \\
Q5 & 0.31254 & 0.337118 & 0.267138 & 0.205253 & 1 & & & \\
Q6 & 0.228144 & 0.246817 & 0.17631 & 0.170343 & $\mathbf{0 . 7 4 6 7 2 9}$ & 1 & & \\
Q7 & 0.280539 & 0.255336 & 0.236204 & 0.215035 & $\mathbf{0 . 6 2 4 5 9 6}$ & $\mathbf{0 . 6 6 9 1 3 2}$ & 1 & \\
Q8 & 0.239977 & 0.260953 & 0.214126 & 0.188441 & $\mathbf{0 . 6 1 6 0 8 4}$ & $\mathbf{0 . 7 6 5 0 1 5}$ & $\mathbf{0 . 7 5 5 7 3 9}$ & 1 \\
\hline
\end{tabular}

Bolded numbers are within correlations for each construct.

Table 5. Questions' loadings from Factor Analysis

\begin{tabular}{|c|c|c|c|}
\hline Construct & Item & & \\
\hline \multirow{5}{*}{ Control Appraisals } & & 1 & 2 \\
\hline & Q1 & 0.872 & 0.141 \\
\hline & Q2 & 0.885 & 0.153 \\
\hline & Q3 & 0.709 & 0.123 \\
\hline & Q4 & 0.544 & 0.125 \\
\hline \multirow{4}{*}{ Value Appraisals } & Q5 & 0.242 & 0.753 \\
\hline & Q6 & 0.121 & 0.88 \\
\hline & Q7 & 0.177 & 0.786 \\
\hline & Q8 & 0.143 & 0.853 \\
\hline Eigenvalues & & 2.761 & 2.467 \\
\hline$\%$ of variance & & 34.5 & 30.8 \\
\hline
\end{tabular}

Bolded numbers are the highest values among the factors.

Learning assessments were validated via face validity to identify the degree to which the test measured a content area (Gay, Mills, \& Airasian, 2011). The face validity of each of the learning assessments was performed by three experts. These included a professor of materials engineering, a postdoctoral researcher in materials engineering, and the course instructor (in this particular case six different instructors, one per course). These experts reviewed the test itself, and then made a judgment about how well items represented the content area. They did so by comparing and aligning the objectives of the learning module, the learning module itself and specific questions in each of the assessments.

\subsection{Procedures}

The procedures for data collection occurred in multiple semesters along with the first iteration of the implementation of the curricular innovation. Figure 2 also indicates when each of the components of the curricular innovation was implemented. For the two iterations of the CPMSE course (the first one in spring 2012 and the second one in spring 2013), self-belief measures were collected at the beginning and at the end of the semester. Findings from the first 
iteration of the CPMSE course (spring 2012) are reported elsewhere (Authors, 2013). Similarly, self-belief measures for each of the six MSE courses were collected at the beginning and at the end of the semester.

For the case of the learning measures, these were collected at the beginning and at the end of the implementation of each of the computational modules. Students engaged with a minimum of one to a maximum of three computational modules in a course, at different times during the semester. Before implementing each of the computational modules a pretest assessment was implemented to identify students' current understanding of disciplinary concepts in the selected area of application. Students then worked on the computational modules during and after class time for a one-week period. During that week, students were able to seek assistance from the professor or the teaching assistant during office hours. Students completed the posttest assessment during the class in which they submitted the module.

\subsection{Data Analysis Method}

Descriptive statistics were used to identify measures of central tendency and variability in the pretest and posttest scores. We examined students' perceptions of computation based on a composite score of the two constructs (Control Appraisals and Value Appraisals). The average scores were interpreted as negative, neutral, and positive if those were in the range of 1 to $<2.5,2.5$ to $<3.5$, and 3.5 to 5 , respectively. The score of learning performance was normalized with the range from 0 to 100 . To compare perceptions and learning gains from pretest to posttest, a paired t-test was carried out for each construct.

Cohen's $d$ test (Cohen, 1988) was used to calculate the effect size for these comparisons. The scale to interpret the effect size is as follow: (1) Weak effect size: $|\mathrm{d}|<0.2$; (2) Weak to moderate: $0.2<|\mathrm{d}|<0.4$; (3) Moderate: $0.40<|\mathrm{d}|<0.65$; (4) Moderate to strong: $0.65<|\mathrm{d}|<0.8$; (5) Strong: 0.8<|d| (Rubin, 2012).

We first wanted to identify how prior programming experiences relate to students' current control and value appraisals. Therefore, students were grouped based on their prior computing experiences and descriptive statistics were calculated for each construct. Pretest and posttest measures were compared using a paired t-test. Afterwards, a one way analysis of variance (ANOVA) was employed to identify differences among groups for the control and value appraisals. For results suggesting significant differences among groups, a post-hoc Tukey test was carried out to identify differences between the groups.

The next step was to correlate the control and value appraisals between them and to academic performance. We employed a Pearson correlation to identify possible interactions between constructs. The correlation coefficient can be interpreted as follows: (1) weak relation: $|\mathrm{r}|<0.1$; (2) weak to moderate: $0.1<|\mathrm{r}|<0.2$; (3) moderate: $0.25<|\mathrm{r}|<0.35$; (4) moderate to strong: $0.35<|r|<0.4$; and (5) strong: $0.5<|r|$ (Rubin, 2012).

\section{Results}

The results from our analyses are presented in terms of student self-beliefs and student disciplinary learning gains of the overall sample size (i.e., all the students participating in the study). We then report student self-beliefs of computation in terms of previous computing courses. Then, we discuss learning gains in terms of previous computing courses. Finally, we present the correlational analysis between students' control and value appraisals, and student performance.

\subsection{Overall Student Self-beliefs and Learning Gains}

The first analysis aimed to answer the question: Are there any differences in self-beliefs among students who have different prior programming experiences? We separately performed the paired t-test on each of the constructs to reveal any significant differences between pretest and posttest measures. The assumptions of normality and homogeneity of 
variances were tested in order to carry out the appropriate test. The data was normally distributed and the variances were homogeneous, therefore, a parametric paired t-test was deemed appropriate for this analysis.

As shown in Table 6, on average, the control appraisals started as neutral on the pretest and remained neutral on the posttest. The results were statistically significant for control appraisals with a moderate to strong effect size (t(129) $=-7.605, \mathrm{p}<.05, \mathrm{~d}=0.67)$. The value appraisals were identified as neutral and stayed at the same level throughout the implementation. No significant differences were found for value appraisals $(t(129)=0.273, p=0.786)$. Table 6 summarizes the descriptive statistics as well as the significant differences for each of the self-beliefs.

Table 6. Overall descriptive statistics and paired t-test on student self-beliefs

\begin{tabular}{|c|c|c|c|c|c|c|c|c|}
\hline \multirow[b]{2}{*}{ Construct } & \multicolumn{2}{|c|}{ Pretest } & \multicolumn{2}{|c|}{ Posttest } & \multirow[b]{2}{*}{$\mathrm{t}$} & \multirow[b]{2}{*}{ DF } & \multirow[b]{2}{*}{ p-value } & \multirow[b]{2}{*}{$\mathrm{d}$} \\
\hline & Mean & Std. Dev. & Mean & Std. Dev. & & & & \\
\hline Self-Beliefs $(\mathrm{n}=130)$ & & & & & & & & \\
\hline Control & 2.51 & 0.93 & 3.06 & 0.80 & -7.61 & 129 & $<.01$ & $0.67 *$ \\
\hline Value & 3.27 & 0.97 & 3.25 & 1.06 & 0.273 & 129 & 0.79 & N/A \\
\hline
\end{tabular}

Significant difference p-value $<0.05$

* Strong effect size

The pretest and posttest scores of all the learning modules were also compared to explore the question: Are there any differences in disciplinary learning among students who have different prior programming experiences? Due to the small sample size for some modules, a non-parametric Welch's paired t-test was employed. Table 7 depicts the descriptive statistics and the inferential tests for learning gains. Eight out of the twelve modules showed a significant difference from pretest to posttest with four of them depicting a strong effect size (d>0.8) and two of them depicting a moderate to strong effect size $0.65<|\mathrm{d}|<0.8$.

Table 7. Overall descriptive statistics and non-parametric t-test on student learning scores of each module

\begin{tabular}{|c|c|c|c|c|c|c|c|c|c|}
\hline \multirow[b]{2}{*}{ Module } & \multirow[b]{2}{*}{$\begin{array}{c}\text { Level of } \\
\text { Access }\end{array}$} & \multicolumn{2}{|c|}{ Pretest } & \multicolumn{2}{|c|}{ Posttest } & \multirow[b]{2}{*}{$\mathrm{t}$} & \multirow[b]{2}{*}{ DF } & \multirow[b]{2}{*}{ p-value } & \multirow[b]{2}{*}{$\mathrm{d}$} \\
\hline & & $\begin{array}{c}\text { Mean } \\
(\%)\end{array}$ & $\begin{array}{c}\text { Std. Dev } \\
(\%)\end{array}$ & $\begin{array}{c}\text { Mean } \\
(\%)\end{array}$ & $\begin{array}{c}\text { Std. Dev. } \\
(\%)\end{array}$ & & & & \\
\hline \multicolumn{10}{|l|}{ Biomaterials } \\
\hline $1(n=65)$ & Configuring & 51.92 & 25.11 & 59.61 & 20.10 & -2.28 & 64 & 0.03 & 0.29 \\
\hline \multicolumn{10}{|l|}{ Structures } \\
\hline $1(n=16)$ & Programming & 53.13 & 20.16 & 51.56 & 30.91 & 0.21 & 15 & 0.84 & N/A \\
\hline $2(\mathrm{n}=9)$ & Configuring & 44.44 & 27.32 & 52.78 & 29.17 & -0.82 & 8 & 0.44 & N/A \\
\hline \multicolumn{10}{|c|}{ Thermodynamics } \\
\hline $1(\mathrm{n}=25)$ & Programming & 50.00 & 16.14 & 50.00 & 25.00 & 0 & 24 & 1 & N/A \\
\hline $2(n=23)$ & Programming & 35.87 & 24.80 & 44.57 & 30.11 & -1.50 & 22 & 0.15 & N/A \\
\hline $3(n=22)$ & Configuring & 32.86 & 20.97 & 44.56 & 23.75 & -3.46 & 21 & $<0.01$ & 0.38 \\
\hline \multicolumn{10}{|c|}{ Electronic Properties } \\
\hline $1(n=14)$ & Programming & 42.86 & 24.86 & 69.64 & 20.04 & -3.16 & 13 & 0.01 & $0.85^{*}$ \\
\hline $2(n=12)$ & Configuring & 27.08 & 24.90 & 50.00 & 26.11 & -2.30 & 11 & 0.04 & 0.67 \\
\hline \multicolumn{10}{|c|}{ Mechanical Properties } \\
\hline $1(n=13)$ & Configuring & 25.00 & 25.00 & 59.62 & 24.02 & -3.45 & 12 & $<0.01$ & $0.96 *$ \\
\hline $2(n=14)$ & Programming & 35.71 & 25.41 & 58.92 & 23.22 & -2.41 & 13 & 0.03 & 0.65 \\
\hline \multicolumn{10}{|c|}{ Kinetics and Phase Transformations } \\
\hline $1(n=16)$ & Configuring & 53.13 & 20.16 & 75.00 & 20.41 & -4.34 & 15 & $<0.01$ & $1.09 *$ \\
\hline $2(n=12)$ & Configuring & 36.53 & 24.19 & 69.23 & 20.80 & -4.57 & 12 & $<0.01$ & $1.28 *$ \\
\hline
\end{tabular}

Significant difference p-value $<0.05$

* Strong effect size

\subsection{Student Self-beliefs in Terms of Prior Programming Experiences}

This analysis identifies the effect of previous computing preparation as well as the preparation through the CPMSE course. Participants were grouped into non-CPMSE, CPMSE taken during the spring 2012 (CPMSE-2012), and 
CPMSE taken during the spring 2013 (CPMSE-2013). The difference between CPMSE-2012 and CPMSE-2013 is that students in CPMSE-2012 took the learning modules after completing the CPMSE course. Thus, the students took the pretest after being exposed to the CPMSE course. On the other hand, students in the CPMSE-2013 were only exposed to CPMSE course and not to the computational modules. Therefore while the data in Table 8 for CPMSE-2012 measures the effect of exposure to modules for students pre-exposed to the CPMSE course, the data for the CPMSE-2013 group measures the effect of the exposure to the CPMSE course itself. In both cases, CPMSE2012 and CPMSE-2013, students only experienced one CPMSE course. Five participants who took CPMSE in both semesters, as well as eight students who were exposed to CPMSE-2013 and the modules simultaneously were removed from the analysis. In addition, the non-CPMSE group was split into groups based on how many other computing courses students previously took: Zero, One, Two, and Three to Five. Therefore, there were six groups in total: Zero, One, Two, Three to Five, CMPSE-2012, and CPMSE-2013. As a side note, the data collection ended in May 2013. Students who took CPMSE 2013 may have eventually experienced the computational modules the following academic year, but the team did not conduct the pretest and posttests during the core courses offered the following academic year.

Table 8 depicts descriptive statistics of the self-beliefs constructs for each of these groups. In general, all groups increased their control appraisals ranging from a moderate to a strong effect size. The group with no previous experience (Zero) and the CPMSE-2013 group showed the highest increment for appraisal beliefs moving from a negative score to a neutral and positive one, respectively. Students in the CPMSE-2012 group showed a positive control appraisal from the pretest and these values increased even more after the exposure to the computational modules. The value appraisals showed a significant increment for students with no previous exposure and a significant decrement for the CPMSE-2013 group. Note that the pretest scores from the CPMSE 2012 group were collected after students had taken the course. In contrast, pretest scores from the CPMSE-2013 group were collected before students were exposed to any course materials. This suggests that the effects of the CPMSE-2012 course on student self-beliefs persisted through the following semester.

Table 8. Descriptive statistics and Welch's paired t-test on student self-beliefs grouped by programming experiences

\begin{tabular}{|c|c|c|c|c|c|c|c|c|}
\hline \multirow[b]{2}{*}{$\begin{array}{l}\text { Self-Beliefs by } \\
\text { Previous Courses }\end{array}$} & \multicolumn{2}{|c|}{ Pre-semester Survey } & \multicolumn{2}{|c|}{ Post-Semester Survey } & \multirow[b]{2}{*}{$\mathrm{t}$} & \multirow[b]{2}{*}{ DF } & \multirow[b]{2}{*}{$\mathrm{p}$-value } & \multirow[b]{2}{*}{ d } \\
\hline & Mean & Std. Dev. & Mean & Std. Dev. & & & & \\
\hline \multicolumn{9}{|l|}{ Zero $(\mathrm{n}=12)$} \\
\hline Control & 1.60 & 0.82 & 2.31 & 0.82 & -3.36 & 11 & $<0.01$ & $0.97 *$ \\
\hline Value & 2.52 & 0.98 & 3.17 & 1.04 & -3.08 & 11 & 0.01 & $0.89^{*}$ \\
\hline \multicolumn{9}{|l|}{ One $(n=38)$} \\
\hline Control & 2.32 & 0.72 & 2.75 & 0.68 & -4.40 & 37 & $<0.01$ & 0.71 \\
\hline Value & 3.01 & 0.97 & 2.98 & 1.10 & 0.21 & 37 & 0.83 & N/A \\
\hline \multicolumn{9}{|l|}{ Two $(n=30)$} \\
\hline Control & 2.70 & 0.89 & 3.09 & 0.66 & -2.84 & 30 & $<0.01$ & 0.53 \\
\hline Value & 3.17 & 0.94 & 3.23 & 1.17 & -0.33 & 30 & 0.74 & N/A \\
\hline \multicolumn{9}{|c|}{ Three to Five $(n=14)$} \\
\hline Control & 3.23 & 0.53 & 3.27 & 0.56 & -0.22 & 13 & 0.83 & N/A \\
\hline Value & 3.29 & 0.81 & 3.20 & 0.93 & 0.47 & 13 & 0.64 & N/A \\
\hline \multicolumn{9}{|c|}{ CPMSE $2012(\mathrm{n}=11)$} \\
\hline Control & 3.86 & 0.44 & 3.89 & 0.60 & -0.21 & 10 & 0.84 & N/A \\
\hline Value & 3.91 & 0.91 & 3.98 & 0.73 & -0.44 & 10 & 0.67 & N/A \\
\hline \multicolumn{9}{|c|}{ CPMSE $2013(n=24)$} \\
\hline Control & 1.98 & 0.61 & 3.44 & 0.84 & -7.7 & 23 & $<0.01$ & $1.6^{*}$ \\
\hline Value & 3.89 & 0.68 & 3.44 & 0.94 & 2.64 & 23 & 0.015 & -0.56 \\
\hline
\end{tabular}

Significant difference p-value $<0.05$

* Strong effect size

(No effect size is reported-i.e., N/A—when no significant differences found). 
One way ANOVA was employed to identify possible differences among the six groups for the control and value appraisals. This analysis intended to explore the question: How do students' prior programming experiences relate to their self-beliefs and their disciplinary learning? Pretest and gain measures for both constructs were analyzed. For the pretest measure, significant differences were found among the groups for the control appraisals $(\mathrm{F}(5,124)=$ 17.87, p-value $<.01)$ and for the value appraisals $(\mathrm{F}(5,124)=5.77$, p-value $<.01)$. The post-hoc analysis on these groups suggests that before being exposed to the computational modules, students in the CPMSE-2012 group perceived a higher competence in using computation successfully (control appraisals) compared to all the other groups except for the Three-to-Five group. Also, students who had taken more courses or the CPMSE course believed that using computation would enhance his or her academic and work performance.

For the gains from pretest to posttest, significant differences were found for control $(\mathrm{F}(5,124)=11.21$, $\mathrm{p}$-value $<$ .01 ), and for value appraisals $(\mathrm{F}(5,124)=2.57$, p-value $=0.02)$. Therefore, post-hoc analyses were carried out for both constructs. Results suggest that students enrolled in CPMSE-2013 improved significantly in their control appraisals as compared to all other groups. Also, students without any prior programming experience improved their value appraisals significantly compared to students in the CPMSE-2013 group, who already described those as positive in the pretest (mean=3.89). Table 9 summarizes the results for the groups that showed significant differences in the pairwise comparison. The Difference column represents the distance between the means for the specific construct. For instance, the average control appraisal on the pretest for students with one prior programming course was 0.71 higher than the average control score for students with zero prior courses.

Table 9. Post-hoc analysis on pretest score of control appraisal and value appraisal using Tukey Method.

\begin{tabular}{lccc}
\hline \multicolumn{1}{c}{ Courses } & Measure & Construct & Difference \\
\hline Zero - One & Pretest & Control & -0.71 \\
Zero - Two & Pretest & Control & -1.10 \\
Zero - Three to Five & Pretest & Control & -1.63 \\
Zero - CPMSE-2012 & Pretest & Control & -2.26 \\
One - Three to Five & Pretest & Control & -0.91 \\
One - CPMSE-2012 & Pretest & Control & -1.55 \\
Two - CPMSE-2012 & Pretest & Control & -1.16 \\
Two - CPMSE-2013 & Pretest & Control & 0.72 \\
Three to Five - CPMSE-2013 & Pretest & Control & 1.25 \\
CPMSE-2012 - CPMSE-2013 & Pretest & Control & 1.88 \\
Zero - CPMSE-2012 & Pretest & Value & -1.39 \\
Zero - CPMSE-2013 & Pretest & Value & -1.36 \\
One - CPMSE-2012 & Pretest & Value & -0.90 \\
One - CPMSE-2013 & Pretest & Value & -0.87 \\
Two - CPMSE-2013 & Pretest & Value & -0.71 \\
\hline CPMSE-2013 - Zero & Gain & Control & 0.75 \\
CPMSE-2013 - One & Gain & Control & 1.02 \\
CPMSE-2013 - Two & Gain & Control & 1.07 \\
CPMSE-2013 - Three To Five & Gain & Control & 1.42 \\
CPMSE-2013 - CPMSE-2012 & Gain & Control & 1.44 \\
CPMSE-2013 - Zero & Gain & Value & -1.09 \\
\hline
\end{tabular}

Only the pairs with significant differences are presented here.

\subsection{Student Learning Gains in Terms of Prior Programming Experiences}

Two different approaches were employed in the computational modules. The configuring approach consisted of students executing COMSOL, Thermo-Calc or MATLAB simulations and interpreting the results. Students took advantage of the computational representation or explored the underlying model or algorithm, but did not have an 
opportunity to implement or alter it (except for the input parameters). The modules using the programming approach were implemented using Mathematica or MATLAB and included computational tasks in which students were required to alter the program underlying the simulation. The average gain in the programming approach (i.e., the average increment from pretest for posttest for all student scores in programming modules) was $8.8 \%$ with a standard deviation of $23.61 \%$, while the values for the average gain in the configuring approach was a mean of $14.11 \%$ with a standard deviation of $27.96 \%$. However, no significant differences were found between the types of computational modules $(\mathrm{t}(104.501)=-1.16$, $\mathrm{p}$-value $=0.246)$.

Table 10 depicts descriptive statistics and paired t-test results aimed to answer the question: How do students' prior programming experiences relate to their disciplinary learning gains before and after exposure to authentic computational learning experiences? In general, computational learning experiences using the configuring approach appeared to help students from all groups and were correlated with significant disciplinary learning gains with strong effect sizes. On the other hand, students exposed to less programming preparation (e.g., Zero) or programming preparation that was not disciplinarily contextualized (e.g., One and Two) showed a smaller effect size using the programming approach than those with CPMSE 2012 as prior programming experience. These results suggest that while students with no or low prior programming experience are able, on average, to learn from configuring modules, this is not the case for the programming modules. Students appeared to require a disciplinarily contextualized (i.e. authentic) introduction to computation to be able to take advantage from the authentic computational learning experiences that required programming.

Table 10. Descriptive statistics and paired t-test on student learning gains grouped by programming experiences

\begin{tabular}{|c|c|c|c|c|c|c|c|c|}
\hline \multirow[b]{2}{*}{ Learning } & \multicolumn{2}{|c|}{ Pretest } & \multicolumn{2}{|c|}{ Posttest } & \multirow[b]{2}{*}{$\mathrm{t}$} & \multirow[b]{2}{*}{ DF } & \multirow[b]{2}{*}{$\mathrm{p}$-value } & \multirow[b]{2}{*}{$\mathrm{d}$} \\
\hline & Mean & Std. Dev. & Mean & Std. Dev. & & & & \\
\hline \multicolumn{9}{|l|}{ Zero } \\
\hline Overall $(n=8)$ & 40.00 & 8.89 & 50.10 & 16.73 & -2.07 & 7 & 0.08 & N/A \\
\hline Configuring $(\mathrm{n}=8)$ & 33.85 & 17.31 & 51.56 & 12.59 & -4.43 & 7 & $<0.01$ & $1.13 *$ \\
\hline Programming $(\mathrm{n}=7)$ & 45.24 & 17.25 & 50.60 & 28.30 & -0.48 & 6 & 0.65 & N/A \\
\hline \multicolumn{9}{|l|}{ One } \\
\hline Overall $(n=34)$ & 48.90 & 22.24 & 52.11 & 21.81 & -0.77 & 33 & 0.44 & N/A \\
\hline Configuring $(\mathrm{n}=32)$ & 42.27 & 28.63 & 48.44 & 24.14 & -1.21 & 31 & 0.23 & N/A \\
\hline Programming $(n=14)$ & 52.26 & 16.49 & 51.01 & 21.92 & 0.22 & 13 & 0.83 & N/A \\
\hline \multicolumn{9}{|l|}{ Two } \\
\hline Overall $(\mathrm{n}=30)$ & 49.44 & 23.87 & 62.22 & 19.72 & -2.43 & 29 & 0.02 & 0.46 \\
\hline Configuring $(n=29)$ & 47.84 & 26.74 & 65.52 & 16.59 & -2.91 & 28 & $>0.01$ & 0.56 \\
\hline Programming $(n=9)$ & 40.28 & 27.80 & 52.78 & 36.86 & -1.38 & 8 & 0.21 & N/A \\
\hline \multicolumn{9}{|l|}{ Three to Five } \\
\hline Overall $(n=12)$ & 45.83 & 23.44 & 63.89 & 22.29 & -2.31 & 11 & 0.04 & 0.66 \\
\hline Configuring $(\mathrm{n}=12)$ & 45.45 & 24.54 & 63.64 & 23.35 & -2.19 & 10 & 0.05 & 0.67 \\
\hline Programming $(n=2)$ & 62.50 & 17.68 & 62.50 & 17.68 & NA & NA & NA & NA \\
\hline \multicolumn{9}{|l|}{ CPMSE 2012} \\
\hline Overall $(n=12)$ & 43.31 & 12.95 & 64.54 & 16.25 & -5.25 & 11 & $<0.01$ & $1.31 *$ \\
\hline Configuring $(\mathrm{n}=12)$ & 46.18 & 16.87 & 67.88 & 16.10 & -3.79 & 11 & $<0.01$ & $1.16^{*}$ \\
\hline Programming $(n=12)$ & 41.06 & 16.72 & 61.76 & 21.09 & -4.36 & 11 & $<0.01$ & $0.98 *$ \\
\hline
\end{tabular}

Significant difference p-value $<0.05$

* Strong effect size

\subsection{Relationship between Student Self-beliefs, and Academic Learning Gains}

Pearson correlations among student self-beliefs and learning gains were performed to answer the following question: How do students' self-beliefs relate to each other and their disciplinary learning gains after exposure to authentic computational learning experiences? The significant correlations (i.e., p-value<0.05) are bolded in Table 11. Many of the groups did not show a significant correlation probably due the small sample size per group. Control and value appraisals presented a moderate to strong correlation on pretest and a moderate one on the posttest. These results 
suggest that students who perceived a high self-efficacy in using computation successfully (control appraisals) reported high perceived value of using computation. However, although being exposed to the authentic computational learning experiences had an impact on control appraisals, this effect was not found for value appraisals. Nevertheless, the relationship between these two variables was overall almost constant. The control appraisals also showed a moderate correlation in the pretest and the posttest with the learning posttest score. The result suggests that student self-perceived control may help them to acquire disciplinary learning gains. Students enrolled in CPMSE 2013 were not included in this analysis because they only completed the self-beliefs survey and did not have any disciplinary learning measures.

Table 11. Correlations between appraisals and academic performance grouped by prior programming experiences

\begin{tabular}{|c|c|c|c|c|c|c|}
\hline \multirow[b]{2}{*}{ Correlations (r / p-value) } & \multicolumn{6}{|c|}{ Previous Computing Courses } \\
\hline & Overall & Zero & One & Two & Three to Five & $\begin{array}{l}\text { CPMSE } \\
2012 \\
\end{array}$ \\
\hline $\begin{array}{l}\text { Control Pretest and } \\
\text { Value Pretest }\end{array}$ & $0.48 /<0.01$ & $0.53 / 0.18$ & $0.38 / 0.04$ & $0.46 / 0.01$ & $0.05 / 0.88$ & $0.48 / 0.13$ \\
\hline $\begin{array}{l}\text { Control Pretest and } \\
\text { Learning Post }\end{array}$ & $0.35 /<0.01$ & $-0.14 / 0.73$ & $0.3 / 0.10$ & $0.25 / 0.20$ & $0.46 / 0.13$ & $0.18 / 0.59$ \\
\hline $\begin{array}{l}\text { Value Pretest and } \\
\text { Learning Post }\end{array}$ & $0.12 / 0.26$ & $-0.05 / 0.91$ & $0.29 / 0.11$ & $-0.26 / 0.18$ & $0.14 / 0.67$ & $0.03 / 0.92$ \\
\hline $\begin{array}{l}\text { Control Posttest and } \\
\text { Learning Post } \\
\text { Value Posttest and }\end{array}$ & $0.32 />0.01$ & $0.05 / 0.91$ & $0.25 / 0.17$ & $0.31 / 0.11$ & $-0.05 / 0.88$ & $0.18 / 0.60$ \\
\hline Learning Post & $0.18 / 0.09$ & $0.21 / 0.61$ & $0.29 / 0.12$ & $0 / 0.99$ & $0.06 / 0.86$ & $0.12 / 0.72$ \\
\hline
\end{tabular}

* Strong correlation $|\mathrm{r}|>0.5$

Significant difference p-value $<0.05$

\section{Discussion}

Computing abilities have been identified by researchers as one of the most influential skills affecting engineering students self-beliefs, together with drive, motivation, and understanding of disciplinary concepts (Hutchison, et al., 2006). Therefore, understanding the effect that different preparation in computing has on undergraduate students' self-beliefs, in addition to their ability to use computing as a cognitive tool, is an important research endeavor that may improve academic achievement as related to the adoption and integration of computation in students' academic and professional careers. Thus, findings from this study are discussed in relation to student self-beliefs and learning gains. Based on our findings, the following observations can be made regarding student self-beliefs.

1. Students exposed to the CPMSE course, a course in which programming was presented in an 'authentic' engineering context, reported consistent increases on student control appraisals that exceeded student control appraisals for those who entered with zero, one or two prior computing courses of unknown design.

2. Overall, students exposed to the computational modules reported increased control appraisals, but to a lesser extent compared to the CPMSE experience; especially when students did not have previous exposure to computational courses.

3. The interventions of disciplinary computational modules had minimal effect on student reported value appraisals.

Previous research about student self-efficacy has identified that students' confidence in their abilities to complete a variety of tasks, specifically mathematical-related tasks in courses at the college level, predicted their future interests in mathematics courses (Lent, Lopez, \& Bieschke, 1991). In engineering contexts it has also been suggested that 
self-efficacy strongly influences choices engineering students may make (Hutchison-Green, et al., 2008). These influences can be positive or negative based on their perceptions of their abilities as related to a particular task (Hutchison, et al., 2006). These same studies have shown that computing abilities and problem-solving abilities, among others, are sources of confidence of engineering students' self-efficacy, with computing abilities as one of the most influential factors (Hutchison-Green, et al., 2008; Hutchison, et al., 2006). Prior research suggests that students' perceptions identifying a given task as useful have been found to be a strong predictor of effort, cognitive engagement (Greene \& Miller, 1996), and subsequently achievement (Cole, Bergin, \& Whittaker, 2008; Johnson \& Sinatra, 2012). Similarly, self-efficacy is a primary cause of perceived usefulness or value (Pajares \& Miller, 1994), and value has also been found to be a strong predictor of effort and subsequently achievement (Cole, et al., 2008; Johnson \& Sinatra, 2012). For instance, in a study that investigated the relationship between students' programming performance and their beliefs of level of importance of a task and how useful and interesting they found it, showed a significant positive correlation between these constructs (Bergin \& Reilly, 2005).

As for student academic performance, the following observations can be made:

1. Most students are able to increase their understanding of disciplinary concepts when using modules implemented through a configuring approach.

2. Students who were previously exposed to the CPMSE course seemed to reliably learn from modules implemented through the programming approach, in addition to benefiting from modules implemented through a configuring approach.

Science educators have made a distinction between "building" computer models and "using" computer models (Clariana \& Strobel, 2007; Feurzeig \& Roberts, 1999). Learners use computer models when they interact with a simulation and also configure a model through the user interface (Alessi, 2002). When learners build computer models they are able to modify the attributes of variables, change the agents that are part of the system, design different subsystems and design different functionalities of that subsystem (Clariana \& Strobel, 2007). In this case study we have made a similar distinction between configuring as using models, and programming as building models. Based on our findings we hypothesize that for those students in this context (i.e., CPMSE and disciplinary courses), with or without prior 'authentic' computing preparation, were able to improve their understanding of disciplinary concepts when they focused on executing and interpreting models (configuring approach). This was in contrast to modules in which students were asked to implement or alter codes (programming approach), in which conceptual learning gains were only observed in the cohort of students who were exposed to prior 'authentic' computing preparation via the CPMSE course. Other possible explanations include the effect of the course instructor and the teaching assistants, the difficulty associated with the subject domain, and the design of the prior programming experiences (not CPMSE), among others. Or perhaps these twelve students were already high achievers, and therefore, acquired higher learning gains from the module.

These findings are consistent with those of others who have investigated the impact of using simulations for conceptual learning that have reported increased performance on conceptual tests (i.e., Brophy, Magana, \& Strachan, 2013; Campbell, Bourne, Mosterman, \& Brodersen, 2002; Fraser, Pillay, Tjatindi, \& Case, 2007; Mackenzie, Earl, Allen, \& Gilmour, 2001). One might thus infer that configuring modules are superior to programming approaches, but it is likely that students learn additional and distinct concepts and skills by coding in the context of disciplinary learning. For instance, literature on the learning sciences is finding evidence to make a considerable case:

...that programming provides an excellent immersion for the skills and practices of engineering; that it makes mathematics applied, concrete, and empowering; that the core concepts of programming belong in any meaningful definition of computational literacy; and that programming provides a rich medium for creative expression and for cultivating the skills of design; and that as a general model-building and toolmaking tool it supports constructionist learning across the curriculum (Hancock, 2003, p. 14). 
Further research is needed to identify how building computer models may foster additional forms of learning (other than conceptual understanding) such as mathematical thinking and algorithmic thinking.

Our prior studies that have evaluated the conceptual challenges of building computer models present some insight into the challenges that may prevent students from achieving conceptual gains from disciplinarily contextualized programming exercises. For instance, a qualitative analysis of 33 think-alouds exploring how students build computational models, revealed two major obstacles students encountered when building these models as part of their learning experiences. One obstacle related to student ability to conduct mappings between the physical model, the mathematical model and the computational model (Authors 2012). The other was the need for further instructional support (scaffolds) to be able to map between different representations (Authors 2012). Authors and colleagues identified a polarity where students who configured and executed models (configuring approach) wanted to program their own tools, while students who were required to program their own model (programming approach) commented on their difficulties implementing the computational part of the assignments. Therefore a balance is needed between the complexity of the task and the supports provided to students.

Finally, as for the relationship between student self-beliefs and their academic performance, the following observations can be made:

1. Student learning measures only moderately correlate with their control appraisals, but not with value appraisals.

2. The CPMSE course seems to provide an important preparation that goes beyond increasing students' control self-beliefs and this preparation seems to effectively enable them to engage in learning during configuring and programming computational modules equally.

Studies that have centered on the role of self-efficacy and mental models in learning how to program have identified that these two components (i.e., self-efficacy and good mental models) are important to knowledge acquisition and transfer of programming skills (Ramalingam, LaBelle, \& Wiedenbeck, 2004). Furthermore, these findings have also identified that self-efficacy is influenced particularly by previous programming experiences (Hasan, 2003) and it increases as students progress through other programming experiences (Ramalingam, et al., 2004). In our study, this seems to be the trend for the students who were exposed to the CPMSE, particularly as related to their control beliefs.

According to the Control-Value Theory of Achievement Emotions (Pekrun, 2006), student-experienced emotions during a specific task will depend on their perceived level of control of the outcome (control appraisals) and the level to what that outcome is important to them (value appraisals). These emotions are hypothesized to influence cognitive resources, motivation, metacognition, and self-regulation having effects on engagement and performance (Pekrun, et al., 2007). In our study we identified overall moderate correlations between control and value appraisals on the pretest scores and on the posttest measures. . Further exploration is required to be able to conclude that student self-beliefs have a direct impact on student academic performance as suggested by literature (Pekrun, et al., 2007).

\section{Implications for Teaching and Learning}

\subsection{Implications for Programming Preparation}

Implications for programming preparation relate to the role of previous computing courses in students' self-beliefs and future academic performance. For the students in this study, previous experience in programming courses (i.e., the CPMSE course) appear to have a larger impact on their self-beliefs than individual computational modules integrated into core disciplinary courses. Specifically, our findings suggest that anchored instruction contextualized in authentic engineering problem solving, and implemented following guidelines of the HPL framework, can have a 
positive effect on student self-beliefs and academic performance. Specifically, the pretest measures suggest that students who were exposed to the CPMSE course before being exposed to the modules (i.e., CPMSE-2012), showed higher control appraisals than those who did not, even when compared to those who had taken multiple standard introductory computing courses. Moreover, students exposed to CPMSE-2012, had a significantly higher value appraisals on the pretest compared to those with zero, or one previous computing course. This result suggests that the control and value appraisals are lasting for the students exposed to the CPMSE course. Interestingly, students who were anticipating being exposed to the CPMSE-2013 course showed significantly higher value appraisals on the pretest than students who had completed zero, one or two previous computing courses. This indicates that some of the effect relating to student value may not come from participation in the course itself, but in the significance that students ascribe to the requirement of a gateway computing course integrated within their first year of disciplinary coursework. Furthermore, the highest increase in control appraisals from the pretest to the posttest were found for those students who were enrolled in the CPMSE-2013. This increment was significantly higher than any other group of students.

As related to learning gains, students previously exposed to the CPMSE course increased their disciplinary knowledge significantly after being exposed to the computational modules using both programming and configuring approaches. Thus, this analysis suggests a noteworthy impact of the CPMSE course on both student self-beliefs and academic performance. Our findings seem to be aligned with previous research that has identified that students learn disciplinary topics and scientific computing better when the topics are taught in an integrated manner instead of learning each topic separately (Guzdial, 1994).

Many engineering programs have delegated the responsibility of teaching computing courses to computer science departments; thus the responsibility of integrating introductory computing with disciplinary learning has typically neither been assumed by computer science nor engineering departments ([NSF], 2011). The consequences of this are that the students do not learn how to apply computational practices to a real-world problem within their discipline ([NSF], 2011). However, this study suggests that integrating computing with disciplinary problem solving can be an appropriate learning mechanism with potential lasting implications for future disciplinary learning. However, we acknowledge that the framework implemented here represents only one of a number of strategies that have been deployed to integrate computation within engineering disciplines including: (a) building programs from existing courses, creating concentrations in computational science and engineering; (b) introducing multidisciplinary teamtaught project courses; (c) incrementally using small add-on courses to supplement conventional courses in mathematics, engineering, and science; and (d) using a particular sub-discipline, such as computer graphics, to introduce key computational science and engineering ideas into regular courses (Turner et al., 2002).

\subsection{Implications for the Integration of Computational Interventions into Disciplinary Courses}

Implications at the pedagogical level relate to the use of a configuring approach when the learning goal is to acquire disciplinary concepts. Our results suggest that students with a broader range of computing preparations may benefit from configuring and executing models, as opposed to programming them. However, further research is needed to investigate how the programming approach can support other forms of learning, such as helping students develop representational competence as well as algorithmic thinking. For instance, in a recent study, Author and colleagues (in review) identified that students had difficulties in configuring and programming computational models; but once they overcame that hurdle, they benefited by identifying their own misunderstandings and by reinforcing conceptual knowledge through visualization. They also identified that having students analyze an engineering (disciplinary) problem, subsequent to implementing a computational model, can provide students with an opportunity to more concretely relate the mathematical representations to their understanding of the underlying engineering concepts. We propose that a combination of both methods can result in deeper learning. Students can start an instructional unit by using simulations to gain deeper understanding of disciplinary concepts. Then, students can build a model by means of a programming approach, in which they will have an opportunity to understand the mathematical model and map that model into an algorithm to be programmed. Once the model has been programmed, it can be 
compared with that of the initial simulation to test and validate the implementation. Students can then use their own new developed model to solve an engineering problem or optimize a design. This process and combination of approaches may result not only in promoting deeper understanding of disciplinary concepts, but it can also help students develop representational fluency by identifying all mappings between the conceptual, mathematical, and computational models. Such skills are an integral part of computational thinking (Wing, 2006), a necessary skill set for students to be able to become not just the users, but the builders of computational tools.

\section{Conclusion, Limitations and Future Work}

In our study we have investigated both, (a) students' performance measured in the form of assessments and (b) students' self-beliefs about their abilities to perform specific tasks and how valuable they perceived them. Investigating self-beliefs, in addition to academic performance, is a valuable endeavor because previous research suggests that students' self-beliefs are related to academic achievement and cognitive engagement. Specifically, the main contribution of this paper relates to the identification of the role of prior programing experiences on engineering students' self-beliefs and academic performance in subsequent courses. This contribution suggests that integration of computation earlier and more often in the engineering curriculum in an authentic and contextualized way is likely to result in meaningful learning from subsequent experiences.

Limitations of this study relate to those from a case study concerned with the issue of generalizability to the population at large. Nonetheless, researchers have made a case that the "context-dependent nature of the knowledge which case studies unearth, on which these critiques to generalizability focus, however, is precisely the source of its methodological strength" (Case \& Light, 2011; Flyvbjerg, 2001). Therefore, case study was particularly appropriate to approach our investigation in order to provide explanatory theory for the experiences of other individuals who are or might be in comparable situations In spite of having a low statistical power for some of the analyses due to the division of students into groups resulting in small sample sizes, the differences were enough to still find significant differences in many of the groups. Furthermore, the strength of our statistical analysis suggests that our findings can be generalized to additional students with similar backgrounds and being exposed to similar interventions (i.e., the reproducibility of the results). Another limitation was related to the validity and reliability of the learning assessments. Although face validity was performed on the learning assessments, additional forms of validity and reliability need to be considered. Thus, our findings also raise questions and opportunities for future research.

First, as related to student self-beliefs, our findings are not consistent with prior research that held a relationship between student control appraisals and learning gains. We see no conclusive evidence of this, and based on our data we hypothesize it was learning gains that were promoting increased control appraisals. It would seem important to justify the particular conditions under which the reverse relationship might arise. Second, as related to learning gains, it is also necessary to explore the effect of building simulations in helping students develop skills in computational thinking necessary to build computational models independently as well as strengthening their general representational fluency skills. Third, it would also be appropriate to investigate other populations in engineering and also in computer science. Further quantitative studies with larger sample sizes would allow us to investigate how the performance on the learning measures for each module may have varied based on the level of prior programming experience. Similarly, in-depth qualitative studies are necessary to investigate the cognitive processes involved in students' use of computation. Specifically, we are interested in finding out how students map between conceptual, mathematical and computational representations and the kinds of cognitive demands different tasks place on students in this regard. We are also interested in identifying how these learning experiences may lead to success or failure and what interventions may mitigate possible cognitive overload that can result. In the process, we will also investigate what kind of emotions students experience while engaging in computing-related tasks as well as the role of motivation, metacognition, and self-regulation. Identifying the interplay of these components will allow us to perform in-depth investigations of how students learn and engage with and about computation, and consequently to design effective learning experiences. 


\section{Acknowledgements}

[Concealed for peer review]

\section{References}

[ABET]. (2013). 2014-2015 Criteria for Accrediting Engineering Programs Engineering Accreditation Commision. Baltimore, MD: ABET.

[ASEE]. (2013). Transforming Undergraduate Education in Engineering (TUEE) Phase l: Synthesizing and Integrating Industry Perspectives. Arlington, VA: American Society for Engineering Education.

[NRC]. (2011). Report of a workshop on the pedagogical aspects of computational thinking National Research Council. Washington, D.C.: National Research Council of the National Academies.

[NSF]. (2011). Report of the High Performance Computing Task Force Advisory committee for cyberinfrastructure task force on high performance computing. Washington, D.C.: National Science Foundation.

[WTEC]. (2009). International assessment of research and development in simulation-based engineering and science (pp. 426). Baltimore, Maryland: World Technology Evaluation Center, Inc.

Alessi, S. (2002). Building versus using simulations Integrated and Holistic Perspectives on Learning, Instruction and Technology (pp. 175-196): Springer Netherlands.

Atman, C. J., Chimka, J. R., Bursic, K. M., \& Nachtmann, H. L. (1999). A comparison of freshman and senior engineering design processes. Design Studies, 20(2), 131-152.

Bandura, A. (1977). Self-efficacy: toward a unifying theory of behavioral change. Psychological review, 84(2), 191.

Baxter, P., \& Jack, S. (2008). Qualitative case study methodology: Study design and implementation for novice researchers. The qualitative report, 13(4), 544-559.

Bergin, S., \& Reilly, R. (2005). The influence of motivation and comfort-level on learning to program. Paper presented at the Proceedings of the PPIG.

Bransford, J. (2000). How people learn: Brain, mind, experience, and school: National Academies Press.

Brophy, S. P., Magana, A. J., \& Strachan, A. (2013). Lectures and Simulation Laboratories to Improve Learners' Conceptual Understanding. Advances in Engineering Education, 3(3), 1-27.

Brown, J. S., Collins, A., \& Duguid, P. (1989). Situated cognition and the culture of learning. Educational Researcher, 18(1), 32-42.

Bryne, B. M. (1996). Academic self-concept: its structure, measurement, and relation to academic achievement. In B. A. Bracken (Ed.), Handbook of self-concept: Developmental, social and clinical considerations (pp. 287-316). New York: Wiley.

Campbell, J. O., Bourne, J. R., Mosterman, P. J., \& Brodersen, A. J. (2002). The effectiveness of learning simulations for electronic laboratories. Journal of Engineering Education, 91(1), 81-87.

Case, J. M., \& Light, G. (2011). Emerging methodologies in engineering education research. Journal of Engineering Education, 100(1), 186-210.

Choi, J.-I., \& Hannafin, M. (1995). Situated cognition and learning environments: Roles, structures, and implications for design. Educational Technology Research and Development, 43(2), 53-69.

Clariana, R., \& Strobel, J. (2007). AECT Handbook of Educational Communications and Technology. 3rd. Ed. In J. M. Spector, M. D. Merril, J. J. G. van Merrienboer \& M. P. Driscoll (Eds.), (pp. 329-344): Mahwah, NJ: Lawrence Erlbaum Associates.

Cohen, J. (1988). Statistical power analysis for the behavioral sciences (2nd ed.). Hillsdale, NJ: Lawrence Earlbaum Associates. 
Cole, J. S., Bergin, D. A., \& Whittaker, T. A. (2008). Predicting student achievement for low stakes tests with effort and task value. Contemporary Educational Psychology, 33(4), 609-624.

diSessa, A. A. (2001). Changing Minds: Computers, Learning, and Literacy. Cambridge: The MIT Press.

Dym, C. L., Agogino, A. M., Eris, O., Frey, D. D., \& Leifer, L. J. (2005). Engineering design thinking, teaching, and learning. Journal of Engineering Education, 94(1), 103-120.

Ehn, P. (1993). Scandinavian design: On participation and skill. Participatory design: Principles and practices, 41-77.

Emmott, S., \& Rison, S. (2008). Towards 2020 science. Science in Parliament, 65(4), 31-33.

Eysenck, H. J. (1976). Case studies in behaviour therapy. London, UK: Routledge.

Feurzeig, W., \& Roberts, N. (1999). Modeling and simulation in science and mathematics education (Vol. 1). New York, N.Y.: Springer.

Flyvbjerg, B. (2001). Making social science matter: Why social inquiry fails and how it can succeed again: Cambridge university press.

Fraser, D., Pillay, R., Tjatindi, L., \& Case, J. (2007). Enhancing the learning of fluid mechanics using computer simulations. Journal of Engineering Education, 96(4), 381-388.

Gannod, G. C., Burge, J. E., \& Helmick, M. T. (2008). Using the inverted classroom to teach software engineering.

Gay, L. R., Mills, G. E., \& Airasian, P. W. (2011). Educational research: Competencies for analysis and applications. New Jersey: Pearson Higher Ed.

Greene, B. A., \& Miller, R. B. (1996). Influences on achievement: Goals, perceived ability, and cognitive engagement. Contemporary Educational Psychology, 21(2), 181-192.

Guzdial, M. (1994). Software-realized scaffolding to facilitate programming for science learning. Interactive Learning Environments, 4(1), 1-44.

Guzdial, M. (2011). From science to engineering. Communications of the ACM, 54(2), 37-39.

Hancock, C. M. (2003). Real-time programming and the big ideas of computational literacy. Massachusetts Institute of Technology.

Hasan, B. (2003). The influence of specific computer experiences on computer self-efficacy beliefs. Computers in Human Behavior, 19(4), 443-450.

Hutchison-Green, M. A., Follman, D. K., \& Bodner, G. M. (2008). Providing a Voice: Qualitative Investigation of the Impact of a First-Year Engineering Experience on Students' Efficacy Beliefs. Journal of Engineering Education, 97(2), 177-190.

Hutchison, M. A., Follman, D. K., Sumpter, M., \& Bodner, G. M. (2006). Factors Influencing the SelfEfficacy Beliefs of First-Year Engineering Students. Journal of Engineering Education, 95(1), 3947.

International_Engineering_Alliance. (2011). Washington Accord Program Outcomes. Washington, DC: International Engineering Alliance.

Johnson, M. L., \& Sinatra, G. M. (2012). Use of task-value instructional inductions for facilitating engagement and conceptual change. Contemporary Educational Psychology.

Jones, B. D., Paretti, M. C., Hein, S. F., \& Knott, T. W. (2010). An analysis of motivation constructs with first-year engineering students: relationships among expectancies, values, achievement, and career plans. Journal of Engineering Education, 99(4), 319-336.

Kinnunen, P., \& Simon, B. (2012). My program is ok - am I? Computing freshmen's experiences of doing programming assignments. Computer Science Education, 22(1), 1-28.

Korzilius, H. (2010). Quantitative analysis in case study. In A. J. Mills, G. Durepos \& E. Wiebe (Eds.), Encyclopedia of case study research (Vol. 2): Sage Publications.

Lage, M. J., Platt, G. J., \& Treglia, M. (2000). Inverting the classroom: A gateway to creating an inclusive learning environment. The Journal of Economic Education, 31(1), 30-43. 
Lent, R. W., Lopez, F. G., \& Bieschke, K. J. (1991). Mathematics self-efficacy: Sources and relation to science-based career choice. Journal of Counseling Psychology, 38(4), 424.

Likert, R. (1932). A technique for the measurement of attitudes. Archives of psychology.

Litzinger, T. A., Meter, P. V., Firetto, C. M., Passmore, L. J., Masters, C. B., Turns, S. R., . . Zappe, S. E. (2010). A cognitive study of problem solving in statics. Journal of Engineering Education, 99(4), 337-353.

Mackenzie, J., Earl, W., Allen, R., \& Gilmour, I. (2001). Amoco computer simulation in chemical engineering education. Journal of Engineering Education, 90(3), 331-345.

Magana, A. J., Falk, L. M., \& Reese, J. M. (2013). Introducing Discipline-Based Computing in Undergraduate Engineering Education. . ACM Transactions on Computing Education., 13(4), 122.

Magana, A. J., \& Mathur, J. I. (2012). Motivation, Awareness, and Perceptions of Computational Science. Computing in Science \& Engineering, 14(1), 74-79.

McKenna, A. F., \& Carberry, A. R. (2012). Characterizing the role of modeling in innovation. International Journal of Engineering Education, 28(2), 263-269.

Murray, T., Winship, L., Bellin, R., \& Cornell, M. (2001). Toward Glass Box Educational Simulations: Reifying Models for Inspection and Design. 2001 Workshop, External Representations in AIED: Multiple Forms and Multiple Roles San Antonio, Texas.[Fichier, 2003: http://www. psychology. nottingham. ac. uk/research/cred it/AIED-ER/murray. pdf).

Pajares, F., \& Miller, M. D. (1994). Role of self-efficacy and self-concept beliefs in mathematical problem solving: A path analysis. Journal of educational psychology, 86(2), 193.

Pekrun, R. (2006). The control-value theory of achievement emotions: Assumptions, corollaries, and implications for educational research and practice. Educational Psychology Review, 18(4), 315341.

Pekrun, R., Frenzel, A. C., Goetz, T., \& Perry, R. P. (2007). The control-value theory of achievement emotions: An integrative approach to emotions in education: Bibliothek der Universität Konstanz.

Ramalingam, V., LaBelle, D., \& Wiedenbeck, S. (2004). Self-efficacy and mental models in learning to program. Paper presented at the ACM SIGCSE Bulletin.

Roth, W. M., \& McGinn, M. K. (1997). Graphing: Cognitive ability or practice? Science Education, 81(1), 91-106.

Rubin, A. (2012). Statistics for evidence-based practice and evaluation: Cengage Learning.

Shaffer, D. W., \& Resnick, M. (1999). "Thick" Authenticity: New Media and Authentic Learning. Journal of interactive learning research, 10(2), 195-215.

Sherwood, R. D., Kinzer, C. K., Hasselbring, T. S., \& Bransford, J. (1987). Macro-contexts for learning: Initial findings and issues. Applied Cognitive Psychology, 1(2), 93-108.

The_Cognition_Technology_Group_at_Vanderbilt. (1990). Anchored instruction and its relationship to situated cognition. Educational Researcher, 2-10.

Turner, P. R., Shiflet, A. B., Cunningham, S., Stewart, K., Phillips, A. T., \& Vakalis, I. E. (2002). Undergraduate computational science and engineering programs and courses. ACM SIGCSE Bulletin, 34(1), 96-97.

Valentine, J. C., DuBois, D. L., \& Cooper, H. (2004). The relation between self-beliefs and academic achievement: A meta-analytic review. Educational Psychologist, 39(2), 111-133.

Whitehead, A. N. (1959). The aims of education. Daedalus, 88(1), 192-205.

Wing, J. M. (2006). Computational thinking. Communications of the ACM, 49(2), 33-35.

Yin, R. K. (2009). Case study research: Design and methods (Vol. 5). Thousand Oaks, California: Sage Publications, Inc. 
